\title{
Creating Data Citations in LaTeX for Economists
}

\author{
Courtney R. Butler, MLS, Brett D. Currier, MSLS, JD
}

\section{A.ZDATA SOURCE TEMPLATE}

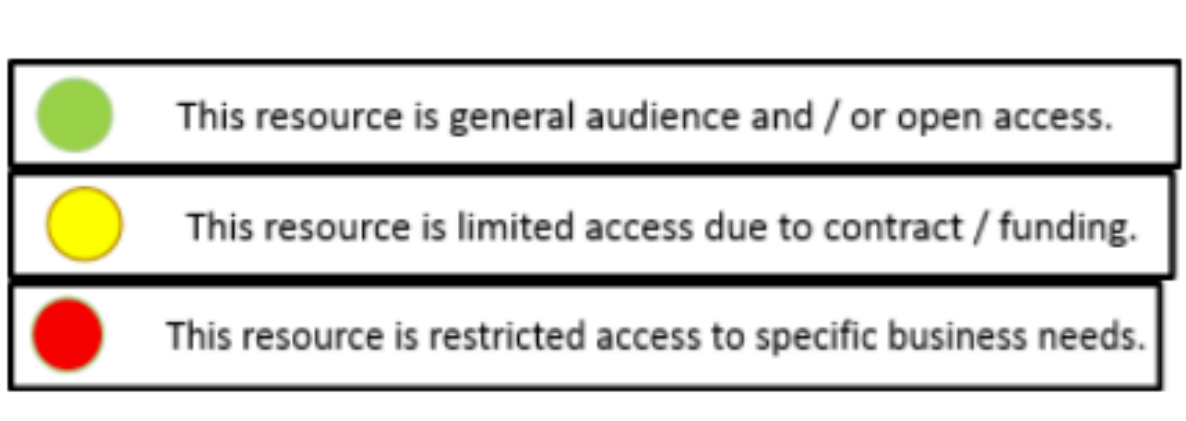

About the Data
Citation liformation

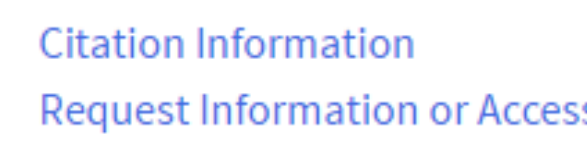

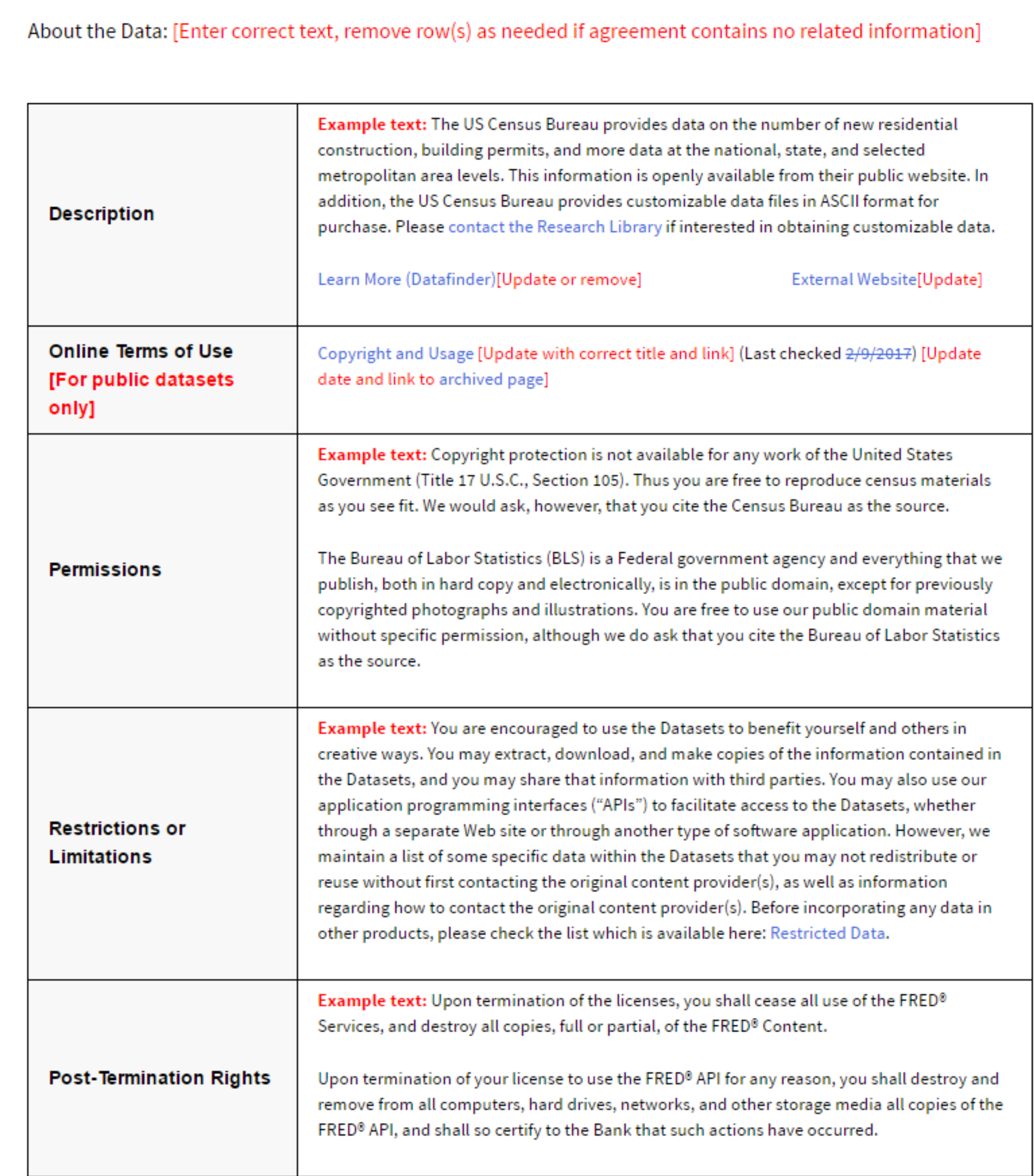

Citation Information:
(see How to cite Vour Data Sources for more general information)

\begin{tabular}{|c|c|}
\hline $\begin{array}{l}\text { In-Text } \\
\text { Citition Format }\end{array}$ & 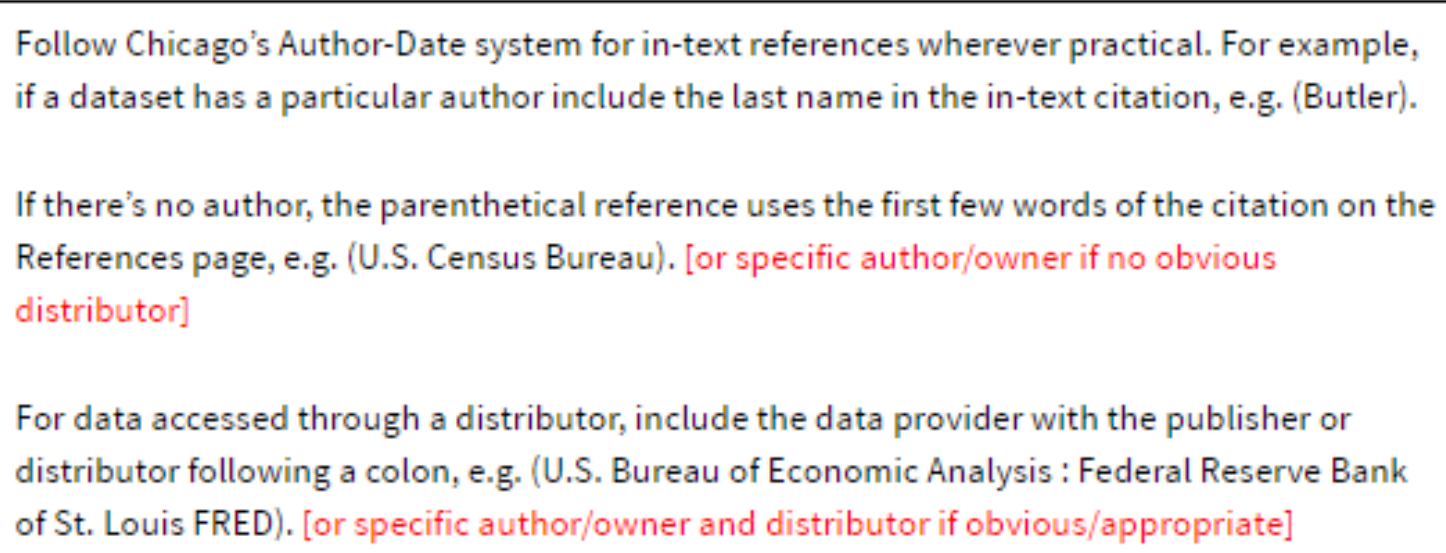 \\
\hline $\begin{array}{l}\text { Table/Graph } \\
\text { chitition fom }\end{array}$ & 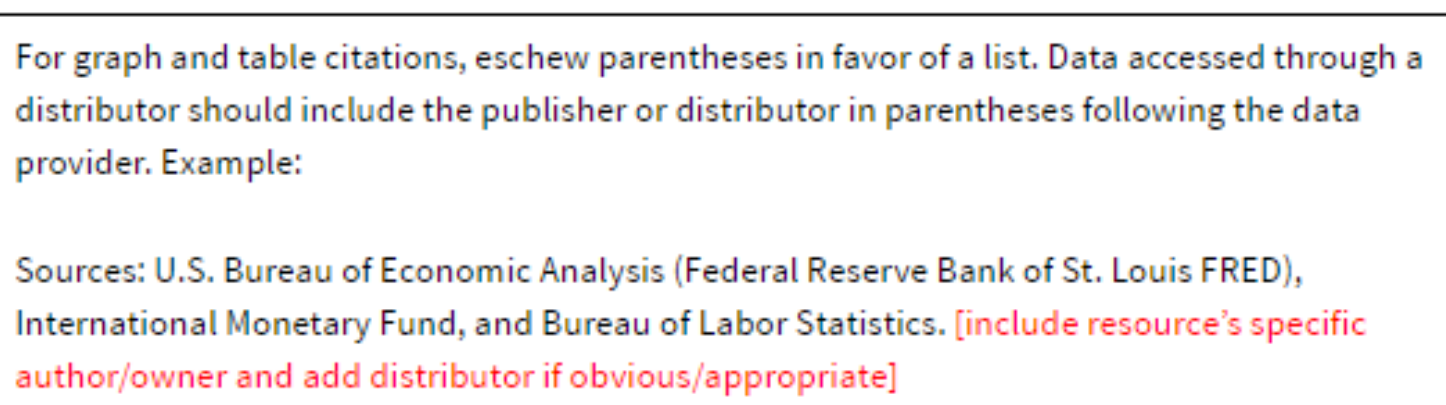 \\
\hline 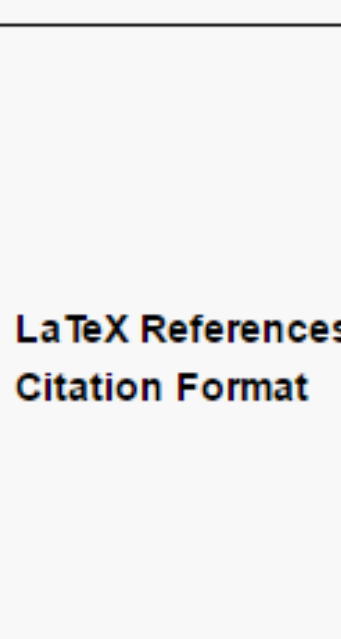 & 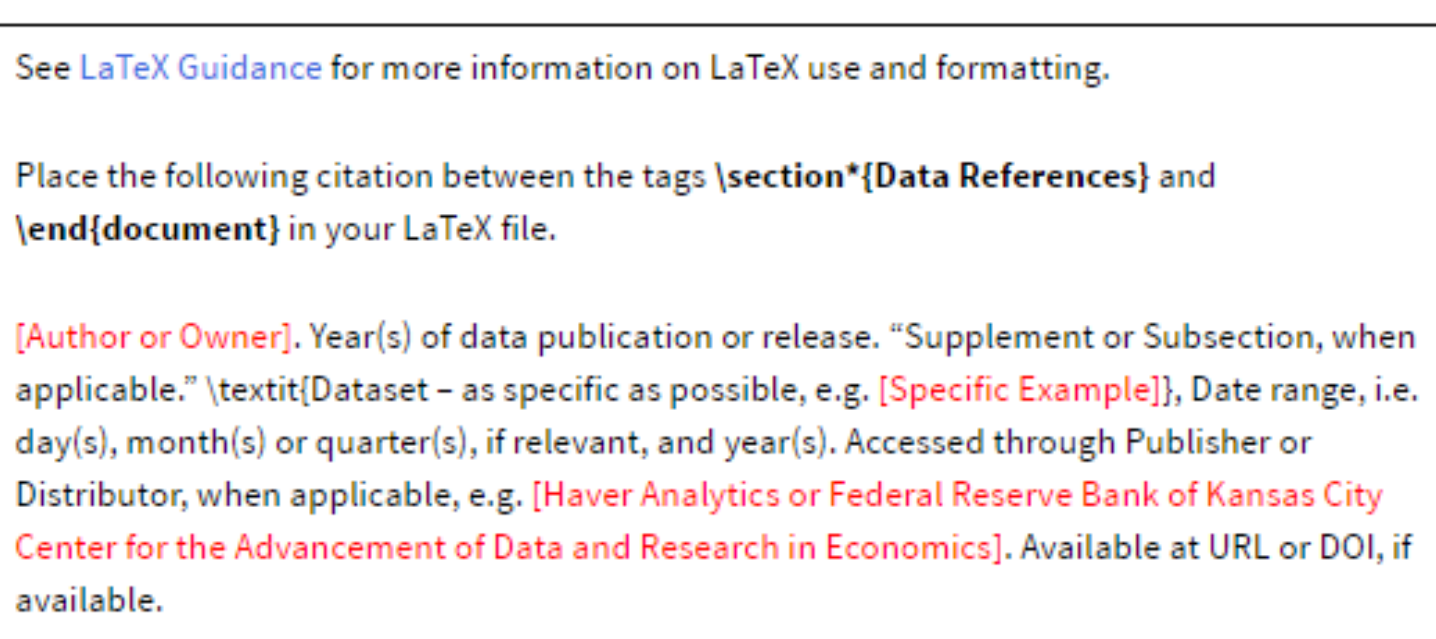 \\
\hline $\begin{array}{l}\text { Word Reterences } \\
\text { Cititition Fomat }\end{array}$ & 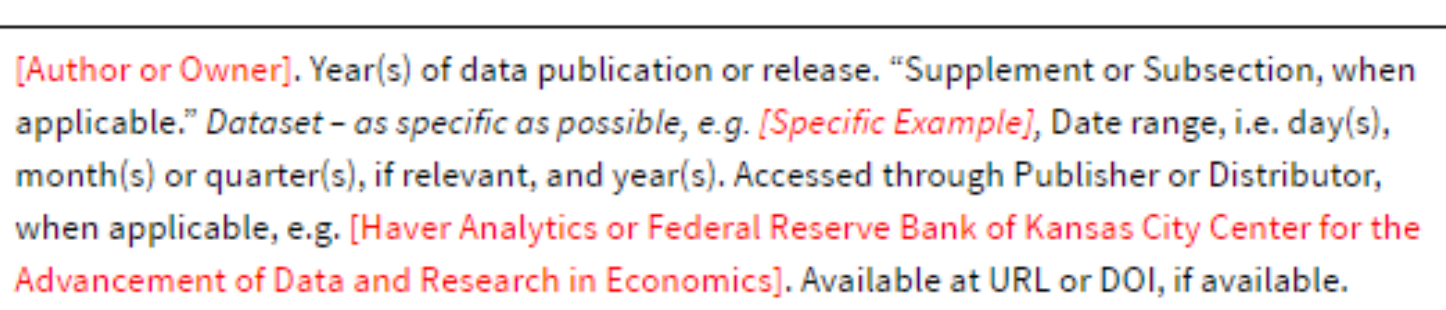 \\
\hline
\end{tabular}

\section{INTRODUCTION}

Copy and paste citation tools, such as Citation Machine and Google Scholar, exist for traditional academic articles and books. These tools provide researchers with the code they need for various citation styles and word processing programs, including LaTeX.
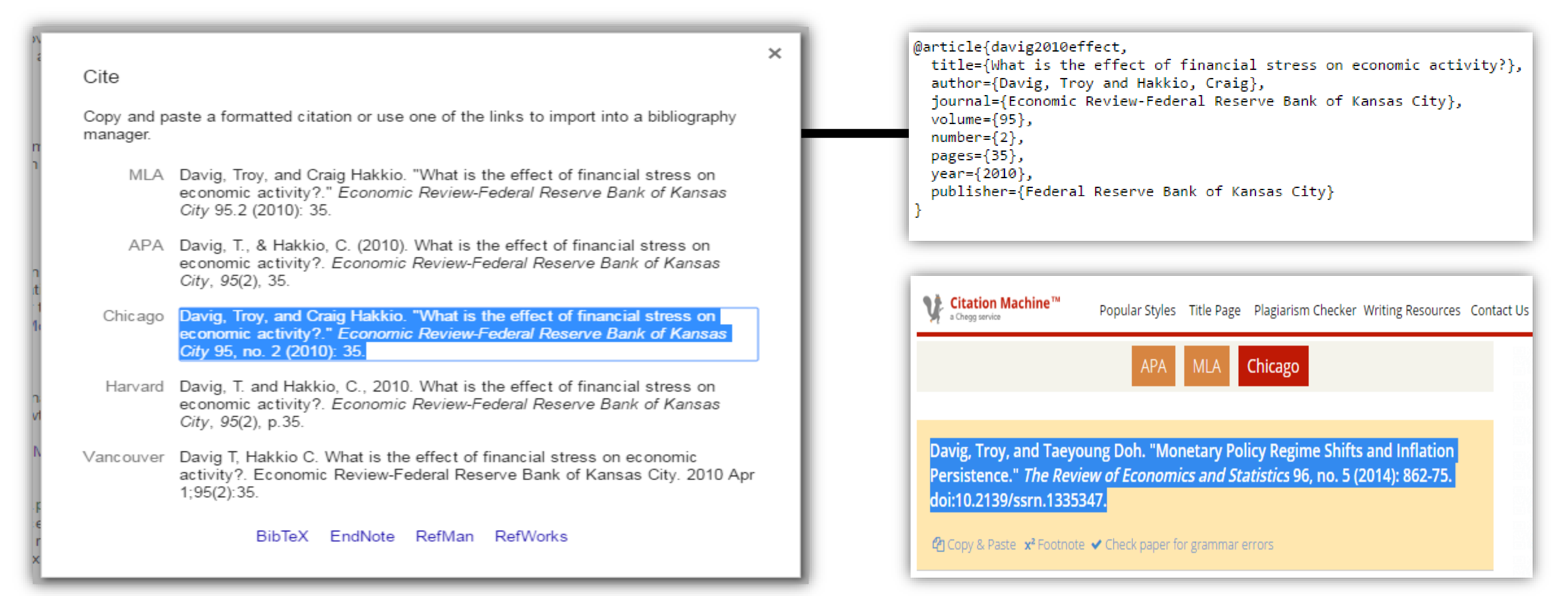

We could not identify a similar plugin for datasets.

\section{PROCESS}

In response, we developed citation templates for all proprietary and select open data sources by reviewing active contracts and online terms of use for:
1. publication permissions, restrictions or limitations,
2. post-termination rights, and
3. specific data citation guidelines.

Vendors were also contacted when citation guidance was not clear. Information was compiled and made available on a private intranet site to avoid violation of non-disclosure agreements.

Citation information was translated into both LaTeX scripting and traditional Microsoft Word format in Modified Chicago Style, taking into account specific citation requirements when indicated by the Licensor, in order to be consistent with in-house publication style.

\section{CONCLUSION}

Having the information compiled in a centralized location with an easy-to-follow template has significantly streamlined the citation process for Bank publications. We will continue to refine and raise awareness of this resource to support ongoing data citation.

Future directions including building a LaTeX library for all datasets, similar to BibTeX, that would allow researchers to insert data citations with a simple command.

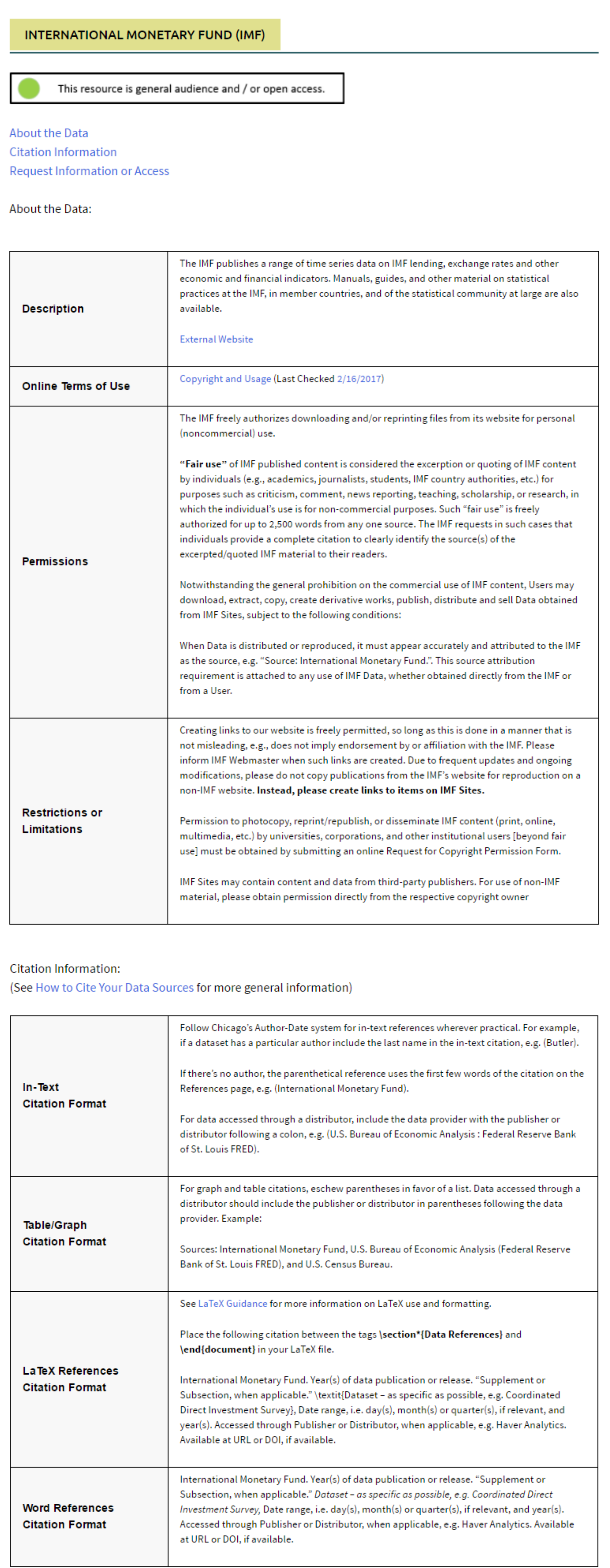

